\title{
PERFIL SOCIAL E PERCEPÇÃO DE FEIRANTES SOBRE AGRICULTURA DE BASE ORGÂNICA E AGROECOLÓGICA
}

\author{
Luanna Cabral de Almeida1', João Manoel da Silva², Sheylla Patrícia Gomes do Nascimento³, Romário \\ Guimarães Verçosa de Araújo르, Clayton dos Santos Silva², Jessé Rafael Bento de Lima ${ }^{4}$, Crisea Cristina \\ Nascimento de Cristo ${ }^{5}$, Tania Marta Carvalho dos Santos², Jakes Halan de Queiroz Costa ${ }^{2}$
}

\author{
${ }^{1}$ Acadêmica do curso de Ciências Biológicas, ICBS, Universidade Federal de Alagoas, Maceió, AL. E-mail: luacabraal@gmail.com \\ ²Laboratório de Microbiologia, CECA, Universidade Federal de Alagoas, Rio Largo, AL. E-mail: jm.agro@hotmail.com; clayton@live. \\ com.pt; romariorgva@hotmail.com; tmcs@ceca.ufal.br; jakes.jakes@gmail.com \\ 3PPGEO, Universidade Federal de Sergipe, Av. Marechal Rondon, Rosa Elze, São Cristóvão, SE. E-mail: sheyllapatricianascimento@ \\ gmail.com \\ ${ }^{4}$ Grupo Agroecológico Craibeiras, CECA, Universidade Federal de Alagoas, Rio Largo, AL. E-mail: jesserafael.adm@hotmail.com \\ ${ }^{5}$ Técnica, Instituto Federal de Alagoas, Campus Murici, Murici, AL. E-mail: criseacncristo@gmail.com
}

\begin{abstract}
RESUMO: A busca por alimentos mais saudáveis e melhoria na saúde vem trazendo à população, a procura por alimentos orgânicos, porém, ainda há dúvidas e desconhecimentos acerca de suas concepções. Por outro lado, há a vertente social da produção agroecológica. Essas duas tentem a confundir a população, onde a mesma crê nas duas como uma só. Cada uma com suas peculiaridades. Diante disso, objetivou-se por meio desse estudo conhecer a percepção de feirantes sobre agricultura de base orgânica e agroecológica em feira livre de duas cidades alagoanas. Para tanto, foi adotado um questionário preestabelecido. Com os dados coletados, foi realizada a tabulação dos mesmos e os dados foram expressos em porcentagem sobre a amostragem total. Ao se analisar os valores e as respostas dos entrevistados, observa-se a forte presença do gênero feminino e de pessoas acima dos 40 anos. União dos Palmares possui feirantes com menores níveis de escolaridade. A percepção mostra que a maioria dos feirantes não possui esclarecimento acerca da diferença entre essas duas bases, além de não conhecer suas definições. Quanto á comparação entre as duas cidades, nota-se que as diferenças encontradas são características quando se avalia o perfil social dos entrevistados, onde a percepção não possui diferenças relevantes.
\end{abstract}

Palavras-chave: feira livre, agroecologia, agricultura orgânica, qualidade alimentar, rurbanidade

\section{SOCIAL PROFILE AND PERCEPTION OF MARKETERS ABOUT AGRICULTURE OF AGROECOLOGICAL AND ORGANIC BASIS}

\begin{abstract}
The search for healthier foods and better health has brought the population, the demand for organic foods, but there are still doubts and misunderstandings about their conceptions. On the other hand, there is the social aspect of agroecological production. These two try to confuse the population, where the same believes in the two as one. Each one with its peculiarities. The objective of this study was to know the perception of marketers on organic and agroecological agriculture in a fair in two cities in Alagoas. Therefore, a pre-established questionnaire was adopted. With the data collected, the data were tabulated and expressed as a percentage of the total sampling. When analyzing the values and the responses of the interviewees, the strong presence of the female gender and of people above 40 years old is observed. União dos Palmares has fairgrounds with lower levels of schooling. The perception shows that most of the marketers do not have clarification about the difference between these two bases, besides not knowing their definitions. As for the comparison between the two cities, it is observed that the differences found are characteristic when the social profile of the interviewees is evaluated, where the perception does not have relevant differences.
\end{abstract}

Keywords: free fair, agroecology, organic agriculture, food quality, rurbanity 


\section{INTRODUÇÃO}

A procura por alimentos saudáveis e preocupação com a melhoria de vida e prevenção de doenças vem ganhando atenção nos últimos anos. Assim, a população vive uma tendência por buscar nos meios de compra e venda, obter alimentos livres de agroquímicos.

Essa procura é impulsionada por correntes que propagam novos métodos de cultivo de plantas alimentícias, como a agroecologia e a agricultura orgânica. Porém, essas duas, mesmo que por caminharem juntas em muitos momentos, distinguemse em função de suas peculiaridades.

A agroecologia possui uma proposta de produção e consumo conscientes, regional e livres do uso de agroquímicos, com objetivo de promover uso integrado de recursos naturais e produção de alimentos juntamente com a biodiversidade, a sociedade e a cooperação (IANOMOTO; TAVARES; FREIXÊDA, 2012). Segundo Ormond et al. (2002) a agricultura orgânica pode ser definida como um conjunto de processos da produção agrícola partindo do suposto básico de que a fertilidade é uma função direta da matéria orgânica do solo, o que remete à manutenção dessa fertilidade revertida, em seguida, em alimentos saudáveis.

Os alimentos orgânicos são aqueles que utilizam, em todos seus processos de produção, técnicas que respeitam o meio ambiente e visam à qualidade do alimento. Desta forma, não são usados agrotóxicos nem qualquer outro tipo de produto que possa vir a causar algum dano à saúde dos consumidores (AZANHA, 2013). Ademais, os sistemas de produção orgânica no Brasil são regulamentados pela Lei Federal $n^{0}$. 10.831, de 23 de dezembro de 2003 (BRASIL, 2003).

Assim, essas duas linhas causam controvérsias quanto às suas ideias. Aagroecologia é concebida como ciência, agricultura orgânica como filosofia, porém, há seu contexto comercial. Essa confusão ideológica acaba que por confundir a população, fazendo com que, hegemonicamente, sejam coisas semelhantes.

Diante do exposto, objetivou-se por meio desse estudo avaliar a percepção de feirantes acerca de alimentos de base orgânica e agroecológica, bem como conhecer o perfil social dos mesmos.

\section{MATERIAL E MÉTODOS}

Para o desenvolvimento da pesquisa, foi realizada a aplicação de questionários preestabelecidos, sendo 30 questionários aplicados.

A pesquisa foi realizada em duas cidades. Foram aplicados 30 questionários na feira livre central do Município de União dos Palmares, localizado na zona da Mata alagoana, e na Cidade de Maceió localizada na Região Metropolitana. As feiras utilizadas no estudo são convencionais e com realização periódica semanal, onde são comercializados diversos produtos de origem agrícola.

As questões foram as seguintes: Escolaridade; Idade; Gênero; Possui filhos; Já consumiu produtos de base orgânica ou agroecológica?; Conhece a diferença entre base agroecológica ou orgânica?; Tem origem da zona rural?; Conhece a origem do produto que comercializa?; Acha importante reduzir o uso de agroquímicos? (justificativa); Quais os danos causados pelos agroquímicos? (dissertativa); 0 que entende sobre agricultura de base orgânica e agroecológica?

Os dados foram tabulados e os resultados expressos em porcentagem sobre a amostra total.

\section{RESULTADOS E DISCUSSÃO}

Com base nos dados coletados, foi possível desenhar um perfil dos feirantes em ambas as localidades, proporcionando a comparação entre as mesmas. Assim, para União dos Palmares, o perfil social mostra que $60 \%$ dos entrevistados possui ensino fundamental incompleto e 16,7\% são analfabetos, com uma faixa etária acima dos 50 anos, refletindo que os feirantes desse município correspondem a uma parcela relativamente envelhecida, o que descreve também a vivência dos mesmos. Quanto a gênero, uma maioria feminina é destacada com $60 \%$ de seu total, porém, isso não reflete 0 empoderamento feminino, uma vez que ainda se conhece o comportamento patriarcal das comunidades rurais, onde os homens, majoritariamente, trabalham nas lavouras, enquanto que as mulheres cuidam da casa, dos filhos e, juntamente ou em separado ao seu cônjuge, comercializam sua colheita. Assim, 77\% afirmam pertencerem à Zona Rural da cidade, ou que nasceram ou que vivem tanto nesta como na Zona Urbana.

Assim, compreende-se que o crescimento urbano alcançou níveis desconhecidos ao longo do 
tempo, levando as cidades a expandirem seus limites físicos sobre o espaço rural, o qual possui identidade própria, modo de vida e organização socioeconômica específica (ALVES; VALE, 2013), o que leva a compreender a interrelação entre os dois meios, hoje conhecido por rurbanização ou rurbanidade.

Quanto ao conhecimento acerca das bases aqui em estudo, 63,3\% afirmam já ter consumido produtos de base orgânica ou agroecológica e 47\% dizem conhecer a diferença entre ambos. Por outro lado, uma parcela de 16,6\% declara que agroecologia e agricultura orgânica são semelhantes. Isso reflete um assombroso aspecto que precisa ser discutido não somente na academia, mas também no seio social, levando o conhecimento à população, especialmente àqueles que disso sobrevivem.

A origem do produto comercializado nas feiras livres, comumente é dos CEASAS (Centrais de Abastecimento), porém, ao se tratar de cidade interiorana e que muitos dos feirantes são advindos da Zona Rural, os mesmos afirmam que maior parte do comercializado é obtido no CEASA, porém também produzem "produtos da época", sempre produzindo e comercializando, logo, 90\% afirmaram conhecer a procedência/origem do produto.

Esses produtores que produzem parte do que vendem afirmam não utilizar agroquímicos em suas lavouras, intitulando estes como "veneno", mas dizem fazer uso do Roundup, e não concebem esse como tóxico, pelo fato de não ser aplicado por sobre as plantas da lavoura, mas apenas no solo, o que reflete uma deficiência gritante quanto à assistência técnica rural para pequenos produtores.

Ao se questionar sobre a redução do uso de agroquímicos, $87 \%$ diz que é necessário, pois esses são capazes de afetar a saúde dos trabalhadores rurais, dos animais, e do meio ambiente. Uma fala que chama a atenção é a seguinte "os danos estão aqui em minhas mãos", onde uma entrevistada, que produz tomates, faz uso de produtos químicos na lavoura sem 0 uso de EPI (Equipamentos de Proteção Individual), além de superdosagens. Quanto aos danos, 90\% relata que os danos causados são doenças (câncer) e danos ambientais. $10 \%$ afirma que não é possível reduzir o uso de agroquímicos e que não conhecem os danos ou que as lavouras precisam deles para conseguir produzir.

Um fato que merece atenção é que $60 \%$ declarou não saber o que é agroecologia ou agricultura orgânica, o que vai de encontro quando se questionados se sabem a diferença e terem afirmado que sim. Além disso, parte dos entrevistados que responderam, dissertaram que os dois são a mesma coisa. Apenas $3 \%$ não opinaram.

Já na cidade de Maceió, o perfil social apresenta diferenças, iniciando pela escolaridade, onde mostra que os feirantes possuem mais instrução educacional com 30\% terem ensino fundamental incompleto, $20 \%$ ensino médio completo e $13,3 \%$ dos feirantes possuírem ensino superior completo. A faixa etária também mostra uma amostragem mais jovem, com destaque entre os 40-44 anos de idade. Igualmente a União dos Palmares, $60 \%$ são do gênero feminino e $76 \%$ possui filhos.

A percepção mostra que $67 \%$ já consumiu produtos de base orgânica ou agroecológica, $40 \%$ não sabe a diferença contrastando com $36 \%$ que afirmam saber. Diferentemente de União dos Palmares, 50\% têm origem da Zona Rural, porém, não vivem lá. Ou seja, numa capital, os feirantes moram na própria cidade, distribuindo-se entre os bairros, geralmente os mais periféricos. Dos feirantes de Maceió, apenas $57 \%$ afirmam saber a origem dos produtos que comercializam.

A necessidade de se reduzir 0 uso de agroquímicos é vista de igual modo, onde $86,7 \%$ acha necessária a redução. Hegemonicamente, o discurso adotado para a redução é baseado na saúde, alegando a necessidade de conservar a saúde do trabalhador rural, do consumidor final, do meio ambiente e conservação do solo. A parcela de 10\% que afirma não ser necessário redução diz: "os agroquímicos causam muitos danos, mas se usados corretamente podem ser produzidos sem culpa".

Ao serem questionados sobre 0 que é agricultura de base orgânica e agroecológica, 64\% afirmaram não saber a diferença. Do restante, alguns declararam que ambos são iguais, possuindo apenas nomes diferentes.

Com base nos dados obtidos nas entrevistas, observa-se a carência do diálogo entre as classes produtor-trabalhador-consumidor-academia, esta última, que "detém conhecimento" não o fornece à população em sua totalidade, ou seja, um conhecimento segmentado, acessível apenas àqueles que possuem acesso direto para tal, por meio de livros, eventos socio-acadêmicos, cartilhas, dentre outros. 
Os meios de comunicação, por sua vez, contribuem para a segmentação do conhecimento, onde 0 que chega às populações menos esclarecidas intelectualmente e monetariamente, são conhecimentos muitas vezes irrelevantes ou dispensáveis. Quando se trata de agricultura orgânica ou produções agroecológicas, a maioria dos programas de TV, por exemplo, transmitem tais informações em canais fechados. Mesmo com a existência de programas que abordem na TV aberta a agricultura, ainda há 0 desinteresse por parte da própria população. 0 mesmo se aplica à internet, hoje com uma grandiosa acessibilidade à população, especialmente em dispositivos portáteis como telefones celulares, porém, ainda assim, não há a devida busca por informações corretas e pertinentes sobre o tema.

Nesse viés, a ideia "Agro é Pop" vendida em rede aberta de TV, vai de encontro ao social, mascarando o perigo por trás da utilização desenfreada de insumos químicos e da exploração, por muitas vezes extrativista, dos recursos naturais, sejam eles as espécies vegetais e animais ou o uso do solo e água.

A percepção, por sua vez, trata de como 0 ator social percebe 0 ambiente e os acontecimentos ao seu entorno. Porém, indo além do perceber, é importante 0 viver. Logo, como dizem os relatos dos entrevistados (dados além dos questionários), mostra que a vivência com o campo é um fator importante. Importante por conta da linguagem quase que própria adquirida por estes, que diariamente estão numa relação quase que simbiótica com o campo.

Ao se falar de agroecologia ou agricultura orgânica, os entrevistados dispersam os pensamentos, por não saberem o que falar, ou melhor, por nunca terem o contato com essas palavras. Onde, eventualmente, as ouviu na TV, mas nunca receberam a explicação do que são/significam, daí o pensamento expresso por muitos de que correspondem à mesma coisa. Porém, ao receberem explicações com definições de ambas as palavras, o diálogo toma novo caminho, onde conseguem expressar melhor seus conhecimentos com base na percepção de sua vivência na feira livre ou em campo trabalhando na lavoura.

\section{CONCLUSÕES}

Os dados apontam que na região adotada para estudo, os feirantes apresentam baixa escolaridade, refletindo no entendimento acerca das concepções das bases de cultivo aqui discutidas.

0 perfil social das duas cidades possui diferenças, especialmente ao se comparar o nível de escolaridade e faixa etária dos entrevistados.

Embora trabalhando direta ou indiretamente com bases de agricultura, os feirantes possuem desconhecimento sobre as mesmas, fazendo-se necessária a interação dos meios de atendimento e assistência rural e movimentos sociais no esclarecimento desses, como por meio de cartilhas, visitas, ou realização de eventos direcionados para essa população.

\section{REFERÊNCIAS}

ALVES, F. D.; VALE, A. R. A relação campo-cidade e suas leituras no espaço. Acta Geográfica, 2013. Ed. Esp., 33-41.

AZANHA, D. Vantagens e desvantagens dos alimentos orgânicos. Disponível em: <http://mulherando.com. $\mathrm{br} /$ saude-2/2011vantagens-edesvantagens-dosalimentos-organicos/>. Acesso em: 20 de outubro de 2018.

BRASIL. Ministério da Agricultura, Pecuária e do Abastecimento. Lei Federal no 10.831 de dezembro de 2003. Dispõe sobre normas para a produção de produtos orgânicos vegetais e animais. Diário Oficial da República Federativa do Brasil, Brasília, DF, 23 dez. 2003. Seção 1, p. 11.

ORMOND, J. G. P.; PAULA, S. R. L.; FAVERET FILHO, P. S. C.; ROCHA, L. T. M. Agricultura Orgânica: quando o passado é futuro. BNDES Setorial: Rio de Janeiro, 2002,15, 3-34.

YANAMOTO, A. T. V.; TAVARES, C. A.; FREIXÊDA, V. M. Cartilha consumidor é um ato político!: rede guandu - produção e consumo responsáveis. Piracicaba: Instituto Terra Mater, 2012. 